\title{
BMJ Open Association between alcohol and drug use and arrest for driving under the influence after crash involvement in a rural area of Norway: a case- control study
}

\author{
Ragnhild Elén Gjulem Jamt, ${ }^{1,2}$ Hallvard Gjerde, ${ }^{1}$ Giovanni Romeo, ${ }^{3}$ \\ Stig Tore Bogstrand ${ }^{1,2}$
}

To cite: Jamt REG, Gjerde H, Romeo G, et al. Association between alcohol and drug use and arrest for driving under the influence after crash involvement in a rural area of Norway: a casecontrol study. BMJ Open 2018;9:e023563. doi:10.1136/ bmjopen-2018-023563

- Prepublication history for this paper is available online. To view these files, please visit the journal online (http://dx.doi. org/10.1136/bmjopen-2018023563).

Received 13 April 2018 Revised 21 September 2018 Accepted 5 October 2018

Check for updates

(c) Author(s) (or their employer(s)) 2018. Re-use permitted under CC BY-NC. No commercial re-use. See rights and permissions. Published by BMJ.

${ }^{1}$ Department of Forensic Sciences, Oslo University Hospital, Oslo, Norway

${ }^{2}$ Department of Nursing Science, Institute of Health and Society, University of Oslo, Oslo, Norway ${ }^{3}$ Department of Biostatistics,

Oslo Centre for Biostatistics and Epidemiology, University of Oslo, Oslo, Norway

Correspondence to

Dr Ragnhild Elén Gjulem Jamt; rmraej@ous-hf.no

\section{ABSTRACT}

Objectives The rate of deaths caused by road traffic crashes is particularly high in rural areas. It has been hypothesised that one factor that may contribute is differences in patterns of alcohol use. The aim was to compare the prevalence of psychoactive substances among crash-involved drivers arrested for suspicion of driving under the influence (DUI) who are tested for alcohol and drugs and recent random drivers in a rural area. Furthermore, we investigated the association between traffic crashes and driving after using alcohol, illicit or medicinal drugs either alone or in combination.

Methods A case-control study was carried out in which the case group consisted of crash-involved drivers arrested for suspicion of DUI from 2000 to 2015. This group was compared with a control group of randomly selected drivers recruited to a roadside survey in normal traffic from 2014 to 2015. The case group consisted of 612 individuals (542 men and 70 women) and the control group of 3027 individuals (2099 men and 927 women). Drug and alcohol screening was performed on blood samples from the cases and samples of oral fluid from the controls.

Results The proportion of psychoactive substances was $81.7 \%$ among cases and $1.6 \%$ among the controls. The prevalence of combinations of psychoactive substances was $18 \%$ among the cases and $0.3 \%$ among the controls. The multivariate regression model analysis identified significant drug interactions.

Conclusion The prevalence of alcohol and drugs was high among the crash-involved drivers arrested for suspicion of DUl by the police. In contrast to earlier published research combinations of different psychoactive substances did not increase the OR for traffic crash involvement more than the single drug with highest $\mathrm{OR}$. The statistical methodology presented in this study should be allied in future studies with greater statistical power to confirm these findings.

\section{INTRODUCTION}

It has been estimated that about 25500 people lost their lives on European roads in
Strengths and limitations of this study

- Statistical methods that take into account the effects of drug combinations when estimating associations between traffic crash involvement and driving under the influence of psychoactive substances was applied in this study.

- The high prevalence of alcohol or drugs among the crash-involved drivers arrested for suspicion of driving under the influence in the present study indicates a considerable selection bias.

- The prevalence of drug combinations among random drivers in normal traffic was low; hence, the statistical model contains low numbers of observations and consequentially high uncertainty.

- More studies with greater statistical power are needed to confirm these findings. The statistical methodology presented in this study should be allied in future studies, because combinations of psychoactive substances are prevalent among crash-involved drivers.

2016. ${ }^{1}$ In addition, it has been estimated that for every death on European roads, another 4 individuals get permanently disabling injuries, 8 are seriously injured and 50 get minor injuries. $^{2}$

One preventable factor of significant importance for the number of deaths and injuries occurring on the roads are impaired driving abilities of the driver caused by intake of alcohol, illicit drugs and medicinal drugs. A great variety of studies using different methodological approaches have demonstrated the elevated risk of being involved in traffic crashes when driving under the influence (DUI) of alcohol or drugs. ${ }^{3}$ While prevalence of DUI of alcohol and the impact of alcohol on the risk of traffic crashes has been studied over 
decades, more knowledge about illicit and medicinal drugs is still highly demanded.

Rurality has been addressed as an individual risk factor for dying from injuries in general. Particularly, the rate of deaths caused by road traffic crashes is high in rural areas. The underlying causes for this rural injury pattern have been discussed, and a broad range of contributing factors has been proposed. Differences in attitudes towards safety measures, differences in road and vehicle safety, in patterns of alcohol use and the time it takes to receive medical attention are just some of the suggested factors. ${ }^{45}$

Finnmark is the northernmost and largest county of Norway. It is of approximately the same geographical size as Denmark $\left(48637 \mathrm{~km}^{2}\right)$ and has about 76000 inhabitants giving a population density of about 1.55 inhabitants per square kilometre.

In 2014-2015, a roadside survey was performed in Finnmark to assess the proportion of drivers who had taken psychoactive substances in normal traffic. ${ }^{6}$ The results from this study are in the present investigation compared with the results of toxicological analysis of blood samples from crash-involved drivers arrested for suspicion of DUI by the police in the same county. Previous research has suggested that crash-involved drivers tend to have used more combinations of drugs, while single drug use is more often observed in study samples from normal traffic. ${ }^{7}$ Statistical methods that take into account the combinations of drugs used was applied in this study.

\section{OBJECTIVE}

1. Compare the prevalence of psychoactive substances among crash-involved drivers arrested for suspicion of DUI who were tested for alcohol and drugs and random drivers in normal traffic in a rural area.

2. To investigate the association between involvement in traffic crashes and DUI of alcohol, illicit or medicinal drugs either alone or in combination by using a multivariate logistic regression model.

\section{METHODS}

\section{Patient and public involvement}

Patients and public were not involved in the design or conduct of this study.

\section{Study design and setting}

In this case-control study, the cases and the controls were drivers in the northernmost county of Norway, Finnmark. The cases were crash-involved drivers arrested by the police due to suspected DUI of alcohol and/or drugs. Blood samples from these drivers were collected for toxicological analysis. The controls were random drivers who participated in a roadside survey carried out in cooperation with the local police and the National Mobile Police Service of Norway. In Norway, the police have the authority to stop drivers at random without any particular suspicion. The participants provided samples of oral fluid for analysis of alcohol and drugs.

\section{Selection of cases}

When the police suspects that a driver is under the influence of alcohol and/or drugs while driving, a blood sample may be taken for a toxicological analysis. This can be done regardless of whether the driver has been involved in a traffic crash. In road traffic crashes, blood samples may also be taken if the police do not suspect alcohol or drug use as part of the crash investigation. The blood samples are sent to the national forensic toxicology laboratory, which is a part of the Department of Forensic Sciences at Oslo University Hospital, for analysis of alcohol and drugs. When a toxicological analysis is requested by the police, a requisition form is submitted along with the blood sample. Anonymous data obtained from these requisition forms were used in this study. These data consisted of information on the sex, the age and the time of apprehension (daytime or nighttime, weekend or weekday). All blood samples from arrested crash-involved drivers submitted by the police in the period from January 2000 to December 2015 were included in this study.

\section{Selection of controls}

Finnmark is a sparely populated rural county with a large total area. It would therefore be practically impossible to do sampling completely by random. To achieve the desired number of participants for the survey, main roads with an annual average daily traffic of 500 motor vehicles or more were selected in the period from September 2014 to October 2015. Further details on the sampling procedure have been published in an earlier paper. ${ }^{6}$ All the stopped drivers were informed about this voluntary and anonymous collection of oral fluid for the testing of alcohol, illicit drugs and medicinal drugs. Whenever an informed consent was given, a sample of oral fluid was collected. In addition, information about age, sex, nationality, time interval and geographical site were recorded.

\section{Ethics}

Data on the arrested drivers are property of the Norwegian Higher Prosecuting Authority, the legal owner of all forensic materials in Norway. No specific approval is needed when compiling statistics on anonymous data. Based on the Norwegian Research Ethics Act of April 2017 and the Act on Medical and Health Research of June 2008, research projects handling anonymous data do not fall under the scope of the Act on Medical and Health Research; hence, no approval from the Regional Committee for Medical and Health Research Ethics was required.

The roadside survey was approved by the Regional Committee for Medical and Health Research Ethics.

\section{Biological samples}

Collection of blood samples from the cases was performed within a short time period after apprehension using $5 \mathrm{~mL}$ Vacutainer tubes containing sodium fluoride and heparin 
(BD Vacutainer Systems, Belliver Industrial Estate, Plymouth, UK). After the arrival at the laboratory in Oslo, the blood samples were kept at $2^{\circ} \mathrm{C}-8^{\circ} \mathrm{C}$ until analysis; normally, this was performed within 4 weeks. After the analysis was completed the blood samples were frozen at $-20^{\circ} \mathrm{C}$.

The oral fluid samples from controls were collected using Quantisal oral fluid collection device (Immunalysis Corporation, Pomona, California, USA). The samples were stored in a cooler bag at approximately $5^{\circ} \mathrm{C}$ for up to 6 hours and then frozen locally at about $-20^{\circ} \mathrm{C}$. After arriving at the laboratory in Oslo, the samples were kept frozen at about $-20^{\circ} \mathrm{C}$ until analysis.

\section{Analysis of alcohol and drugs}

The screening methods of the blood samples consisted of an enzymatic method for alcohol, ${ }^{8}$ and for illicit or medicinal drugs, the screening consisted of an immunological method and/or liquid chromatography with mass spectrometric detection (LC-MS) method. The samples with a positive screening result for alcohol were quantified by gas chromatography. ${ }^{9}$ Drug findings were confirmed and quantified using LC-MS or similar methodologies. The laboratory has been accredited according to ISO 17025 for performing the confirmation and quantification methods for forensic toxicology purposes (Norsk Akkreditering, Lillestrøm, Norway).

The oral fluid samples were analysed for alcohol using an enzymatic method ${ }^{8}$ and for illicit and medicinal drugs using ultra performance liquid chromatography-tandem mass spectroscopy (UPLC-MS/MS) ${ }^{6}$

For 17 of the included substances, the legislative concentration limits that were introduced in Norway in February $2012^{10}$ were used as cut-off concentrations in blood. The equivalent cut-off concentrations in oral fluid for 13 of these substances were calculated from formulas developed by the DRUID Project. ${ }^{71}$ For codeine, diazepam and flunitrazepam cut-off concentrations in oral fluid described by Bogstrand and Gjerde ${ }^{7}$ were used. The analytical cut-off concentrations in oral fluid were used for buprenorphine and phenazepam as no recommended cut-off concentrations in oral fluid were available. For 7-aminoclonazepam, no legislative concentration limit exists in Norway and so the recommended cut-off concentration in blood with equivalent cut-off concentration in oral fluid derived from the DRUID project was applied. The blood samples had not been analysed for benzoylecgonine, but the oral fluid samples were analysed for this substance using the recommended cut-off concentration in oral fluid from the DRUID project (table 1).

\section{Statistical testing}

Adjusted ORs were calculated using multivariate logistic regression. The dependent variable was traffic crash (yes/ no). Covariates were sex (with baseline corresponding to male), age (in completed years, with baseline 18 years), time of day (daytime: 08:00-19:59, night-time: 20:0007:59) and weekend (Friday 20:00-Monday 07:59) versus weekdays (Monday 08:00-Friday 19:59). Alcohol and
Table 1 Cut-off concentrations in whole blood and oral fluid

\begin{tabular}{|c|c|c|}
\hline Substance & $\begin{array}{l}\text { Cut-off } \\
\text { in whole } \\
\text { blood (ng/ } \\
\mathrm{mL})\end{array}$ & $\begin{array}{l}\text { Cut-off in } \\
\text { oral fluid } \\
(\mathrm{ng} / \mathrm{mL})\end{array}$ \\
\hline Alcohol (ethanol) & $0.01 \mathrm{~g} / \mathrm{dL}$ & $0.01 \mathrm{~g} / \mathrm{dL}$ \\
\hline 7-aminoclonazepam & $10^{*}$ & $3.1^{*}$ \\
\hline Alprazolam & $3+$ & $1.1 \neq$ \\
\hline Amphetamine & $41 \dagger$ & $740 \ddagger$ \\
\hline Benzoylecgonine & - & $95^{\star}$ \\
\hline Buprenorphine & $0.37 \dagger$ & $12 \S$ \\
\hline Clonazepam & $1.3 \dagger$ & 0.239 \\
\hline Cocaine & $24 \dagger$ & $498 \rrbracket$ \\
\hline Codeine & $100 \ddagger$ & $680 \neq$ \\
\hline Diazepam & $57 \dagger$ & $2.2 \ddagger$ \\
\hline Flunitrazepam & $1.6 \dagger$ & $0.23 \ddagger$ \\
\hline Meprobamate & $1091^{\star *}$ & $1000 \S$ \\
\hline Methadone & $25 \dagger$ & 54ף \\
\hline Methamphetamine & $45 \dagger$ & $930 \ddagger$ \\
\hline Morphine & $9 \dagger$ & $86 \ddagger$ \\
\hline Nitrazepam & $17 \dagger$ & $1.5 \ddagger$ \\
\hline Nordiazepam & $108+$ & 5.99 \\
\hline Oxazepam & $172 \dagger$ & $45 \ddagger$ \\
\hline Phenazepam & $1.8 \dagger$ & $0.5 \S$ \\
\hline Phenobarbital & $4640^{\star *}$ & $20 \S$ \\
\hline Tetrahydrocannabinol & $1.3 \dagger$ & $39 \ddagger$ \\
\hline Zolpidem & $31 \dagger$ & $8.5 \ddagger$ \\
\hline Zopiclone & $12 \dagger$ & $30 \ddagger$ \\
\hline
\end{tabular}

${ }^{*}$ Cut-off concentrations in blood and oral fluid from the DRUID project. ${ }^{11}$

†Legislative limit in Norway from February 2012 or 2016.

$\ddagger$ Equivalent cut-off concentrations in oral fluid described by Bogstrand and Gjerde. ${ }^{7}$

§Analytical cut-off concentrations in oral fluid. ${ }^{6}$

qEquivalent cut-off concentrations in oral fluid calculated using formulae determined by the DRUID project. ${ }^{11}$

${ }^{* *}$ Analytical cut-off concentrations in blood.

drugs were included in the model through dichotomous variables, with 1 corresponding to concentrations equal to or above the cut-of limits (table 1). Due to insufficient sampling of controls during the summer months, we decided to exclude the season variable from the analysis. Covariates that did not significantly predict the outcome were excluded from the final model. All statistical analyses were made in SPSS Statistics V.23. The level of statistical significance was $\mathrm{p} \leq 0.05$.

\section{RESULTS}

\section{Participants}

In the period from January 2000 to December 2015, blood samples from 637 crash-involved drivers arrested 
Table 2 Characteristics of 'cases' and 'controls'

\begin{tabular}{|c|c|c|c|}
\hline & $\begin{array}{l}\text { Cases } \\
(n=612)(\%)\end{array}$ & $\begin{array}{l}\text { Controls } \\
(n=3027)(\%)\end{array}$ & $P$ values \\
\hline \multicolumn{4}{|l|}{ Gender } \\
\hline Men & 88.6 & 69.3 & 0.000 \\
\hline Women & 11.4 & 30.6 & \\
\hline \multicolumn{4}{|l|}{ Age groups (years) } \\
\hline$<25$ & 33.2 & 16.2 & 0.000 \\
\hline 25-34 & 38.2 & 16.0 & 0.000 \\
\hline $35-44$ & 11.8 & 18.3 & 0.000 \\
\hline $45-54$ & 8.7 & 20.2 & 0.000 \\
\hline $55-64$ & 4.1 & 17.0 & 0.000 \\
\hline$>64$ & 4.1 & 12.3 & 0.000 \\
\hline \multicolumn{4}{|l|}{ Season } \\
\hline $\begin{array}{l}\text { Spring (March- } \\
\text { May) }\end{array}$ & 25.3 & 26.2 & 0.664 \\
\hline $\begin{array}{l}\text { Summer (June- } \\
\text { August) }\end{array}$ & 30.7 & 11.6 & 0.000 \\
\hline $\begin{array}{l}\text { Autumn } \\
\text { (September- } \\
\text { November) }\end{array}$ & 23.8 & 37.2 & 0.000 \\
\hline $\begin{array}{l}\text { Winter } \\
\text { (December- } \\
\text { February) }\end{array}$ & 20.1 & 25.0 & 0.015 \\
\hline \multicolumn{4}{|l|}{ Time of day } \\
\hline Day (08:00-19:59) & 36.8 & 63.8 & 0.000 \\
\hline $\begin{array}{l}\text { Night (20:00- } \\
07: 59)\end{array}$ & 63.2 & 36.2 & \\
\hline
\end{tabular}

for suspicion of DUI were submitted by the police in Finnmark for the analysis of alcohol, illicit drugs and medicinal drugs. As only drivers who were 18 years and older could be included in the roadside survey, 25 younger drivers were excluded from this study. The age of 74 of the crash-involved drivers was not recorded; for those cases, the mean age of the case group (32 years) was used. Data from 612 cases are included in the study.

A total of 3228 random drivers were asked to participate in the roadside survey. Of these, 201 drivers refused to participate, leaving a total of 3027 participants. This gave a participation rate of $94 \%$. For one of these drivers, data on gender were not recorded. The mean age of the control group (41 years) was used for one driver whose age was not recorded.

Data on either month, day of the week and time of the day for when the traffic crash occurred were not recorded for 107 of the cases. The same was the case for when the data collection took place for four of the controls. These cases and controls were excluded from the multivariate analysis but included in the bivariate descriptive analysis.

A significant difference was found between the cases and the controls regarding the gender distribution (table 2). Among the cases, $88.6 \%$ were men compared
Table 3 Prevalence of substances in blood samples (cases) and oral fluid samples (controls)

\begin{tabular}{|c|c|c|}
\hline Substance & $\begin{array}{l}\text { Cases } \\
(n=612)(\%)\end{array}$ & $\begin{array}{l}\text { Controls } \\
(n=3027)(\%)\end{array}$ \\
\hline Any substance & 81.7 & 1.6 \\
\hline Alcohol (ethanol) $\geq 0.02 \mathrm{~g} / \mathrm{dL}$ & 67.0 & 0.2 \\
\hline Illicit drugs & 15.2 & 0.6 \\
\hline THC & 9.8 & 0.4 \\
\hline $\begin{array}{l}\text { Amphetamine and/or } \\
\text { methamphetamine }\end{array}$ & 8.5 & 0.2 \\
\hline Amphetamine & 5.9 & 0.1 \\
\hline Methamphetamine & 5.1 & 0.1 \\
\hline Cocaine or benzoylecgonine & 0.2 & 0.1 \\
\hline Benzoylecgonine & - & 0.1 \\
\hline Cocaine & 0.2 & 0 \\
\hline Medicinal drugs & 18.0 & 0.9 \\
\hline Diazepam or nordiazepam & 8.2 & 0.3 \\
\hline Diazepam & 7.7 & 0.2 \\
\hline Nordiazepam & 5.4 & 0.1 \\
\hline $\begin{array}{l}\text { Clonazepam or } \\
\text { 7-aminoclonazepam }\end{array}$ & 4.2 & 0.1 \\
\hline 7-aminoclonazepam & 0.7 & 0 \\
\hline Clonazepam & 4.2 & 0.1 \\
\hline Alprazolam & 3.8 & 0.1 \\
\hline Zopiclone & 2.3 & 0.2 \\
\hline Oxazepam & 2.3 & 0 \\
\hline Morphine & 2.1 & 0 \\
\hline Flunitrazepam & 1.6 & 0 \\
\hline Buprenorphine & 1.3 & 0 \\
\hline Meprobamate & 1.3 & 0 \\
\hline Codeine & 1.0 & 0 \\
\hline Zolpidem & 0.5 & 0.1 \\
\hline Methadone & 0.2 & 0 \\
\hline Nitrazepam & 0.2 & 0 \\
\hline Phenazepam & 0.2 & 0.1 \\
\hline Phenobarbital & 0 & 0.1 \\
\hline
\end{tabular}

THC, tetrahydrocannabinol.

with the control group where the proportion was $69.3 \%$ $(\mathrm{p}=0.000)$. Also when age groups were compared, significant differences were found; $71.5 \%$ of the cases were under the age of 35 years versus $32 \%$ of the controls $(\mathrm{p}=0.000)$.

\section{Alcohol and drug findings}

The prevalence of alcohol and drugs are shown in table 3. In total, $81.7 \%$ of the cases and $1.6 \%$ of the controls tested positive for alcohol and/or drugs. Although the concentrations of drugs in oral fluid do not correlate very well with concentrations in blood, we assume that the alcohol and drug prevalence in oral fluid among controls was 
about the same as in blood when using equivalent cut-off concentrations for oral fluid and blood.

Significant differences in the prevalence of alcohol were found between the two groups. Among the cases, the prevalence of alcohol was $67.0 \%$ and among the controls only $0.2 \%(p=0.000)$. In total, the prevalence of illicit drugs among the cases was $15.2 \%$ and $0.6 \%$ among the controls. The most prevalent illicit drug in both groups was tetrahydrocannabinol (THC) $(9.8 \%$ among cases, $0.4 \%$ among controls).

Of the medicinal drugs, the total prevalence was $18.0 \%$ among the cases and $0.9 \%$ among the controls. Diazepam and clonazepam were the most prevalent substance among the cases $(7.7 \%$ and $4.2 \%$, respectively), while among the controls, the most prevalent substances were diazepam and zopiclone ( $0.2 \%$ for both substances).

The prevalence of combinations of drugs was low among controls $(0.3 \%)$, and alcohol was not found in any combination. The most prevalent combination was amphetamine or methamphetamine and diazepam found in $0.1 \%$ of the samples. In the case group, combinations were found in $18.0 \%$ of the samples, and the most prevalent combination was benzodiazepines and alcohol found in approximately $6.7 \%$ of the samples. On average, those drivers who tested positive for benzodiazepines and similar substances were positive for 1.2 substances in the control group and 1.5 substances in the case group.

\section{Estimation of $\mathrm{OR}$ for involvement in a toxicologically investigated road traffic crash}

To estimate the adjusted OR for involvement in a toxicologically investigated road traffic crash, a multivariate logistic regression model has been considered. We first estimated the complete model including as covariates: gender, age, time of day, weekday/weekend and all the covariates indicating the influence of alcohol or drugs. Then with a backward stepwise procedure, a reduced model was selected. The procedure found the effect of the variables time of day and weekday/weekend to not be statistically significant $(\mathrm{F}$-test $=1.424$, $\mathrm{p}$ value $=0.491)$. The reduced model with estimated coefficients and ORs are reported in table 4 .

The highest adjusted OR was found for the total use of alcohol (OR=976.8, 95\% CI 450.8 to 2116.9).

To this model several variables were consequentially added to test drug interactions of which only the statistically significant are shown in table 5 . When the interaction covariate 'amphetamine and/or methamphetamine combined with THC' was entered into the model, the results showed that the OR for involvement in a traffic crash when under the influence of both amphetamine and/or methamphetamine and THC was not additive, but rather approximated the highest of the ORs for the individual substances of the interaction: amphetamine and/ or methamphetamine (table 5: $\mathrm{B}=5.144, \mathrm{OR}=171.3(95 \%$ CI 29.7 to 990.1)) (as can be seen when the coefficients of 'Amph.+Methamph.' (B=5.144) and 'THC' $(\mathrm{B}=2.727)$ and 'Amph.+Metamph. combined with THC' $(\mathrm{B}=-2.909)$ are added together; $(\mathrm{B}=4.962$; in OR scale 142.9 (95\% CI 22.0 to 927.5$)$ ). The same was the case for the interaction 'amphetamine and/or methamphetamine combined with benzodiazepines and similar substances' that estimated the combined effect (OR of 109.9 (95\% CI 26.0 to 463.0) ) to approximate the largest of the two individual effects (amphetamine and/or methamphetamine: OR of 171.3 (95\% CI 29.7 to 990.1 ).

For the interaction 'clonazepam combined with other benzodiazepines and similar substances' (OR of 23.7 (95\% CI 3.5 to 160.8$)$ ), the combined effect can be seen as an average effect of the two individual drug effects (clonazepam: OR of 41.5 (95\% CI 3.7 to 464.4 ) and benzodiazepines and similar substances: OR of $21.0(95 \%$ CI 9.9 to 44.4$)$ ).

The inclusion of the interactions in the model resulted in a larger estimated individual effect for 'amphetamine

Table 4 Multivariate analysis of involvement in traffic crashes and driving under the influence of alcohol, illicit or medicinal drugs

\begin{tabular}{lllcrr} 
& & & & \multicolumn{2}{c}{$95 \%$ Cl for Exp (B) } \\
\cline { 5 - 6 } Variables & B & Sig. & Exp (B) & Lower & Upper \\
\hline Gender & -0.793 & 0.000 & 0.5 & 0.3 & 0.7 \\
Age & -0.036 & 0.000 & $1.0^{\star}$ & $1.0^{*}$ & $1.0^{*}$ \\
Alcohol & 6.884 & 0.000 & 976.8 & 450.8 & 2116.9 \\
Amphetamine/methamphetamine† & 3.443 & 0.000 & 31.3 & 10.8 & 90.6 \\
Clonazepam & 2.208 & 0.007 & 9.1 & 1.9 & 44.6 \\
Tetrahydrocannabinol & 2.463 & 0.000 & 11.7 & 5.0 & 27.9 \\
Zopiclone & 2.494 & 0.000 & 12.1 & 3.0 & 49.0 \\
Benzodiazepines and similar substances $\neq$ & 2.539 & 0.000 & 12.7 & 6.1 & 26.2 \\
\hline
\end{tabular}

*Numbers are rounded off from $\operatorname{Exp}(B)=0.964 \%$ and $95 \% \mathrm{Cl}$ for $\operatorname{Exp}(\mathrm{B}): 0.953-0.975$.

†Samples positive for amphetamine and/or methamphetamine.

‡Benzodiazepines and similar substances: alprazolam, diazepam, etizolam, flunitrazepam, meprobamate, nitrazepam, nordiazepam, oxazepam, phenazepam, phenobarbital and zolpidem. 
Table 5 Multivariate analysis of involvement in traffic crashes and driving under the influence of alcohol, illicit or medicinal drugs, including combinations of drugs

\begin{tabular}{|c|c|c|c|c|c|}
\hline \multirow[b]{2}{*}{ Variables } & \multirow[b]{2}{*}{ B } & \multirow[b]{2}{*}{ Sig. } & \multirow[b]{2}{*}{$\operatorname{Exp}(B)$} & \multicolumn{2}{|c|}{ 95\% Cl for $\operatorname{Exp}(\mathrm{B})$} \\
\hline & & & & Lower & Upper \\
\hline Gender & -0.833 & 0.000 & 0.4 & 0.3 & 0.7 \\
\hline Alcohol & 6.919 & 0.000 & 1011.1 & 466.2 & 2192.8 \\
\hline Amphetamine/methamphetamine† & 5.144 & 0.000 & 171.3 & 29.7 & 990.1 \\
\hline Tetrahydrocannabinol & 2.727 & 0.000 & 15.3 & 6.0 & 39.0 \\
\hline Zopiclone & 2.356 & 0.002 & 10.6 & 2.5 & 45.3 \\
\hline Benzodiazepines and similar substancesł & 3.043 & 0.000 & 21.0 & 9.9 & 44.4 \\
\hline Amphetamine+methamphetamine combined with THC & -2.909 & 0.009 & & & \\
\hline $\begin{array}{l}\text { Amphetamine+methamphetamine combined with } \\
\text { benzodiazepines and similar substances }\end{array}$ & -3.486 & 0.001 & & & \\
\hline
\end{tabular}

${ }^{*}$ Numbers are rounded off from $\operatorname{Exp}(B)=0.965 \%$ and 95\% Cl for Exp (B): 0954-0976.

†Samples positive for amphetamine and/or methamphetamine.

‡Benzodiazepines and similar substances: alprazolam, diazepam, etizolam, flunitrazepam, meprobamate, nitrazepam, nordiazepam, oxazepam, phenazepam, phenobarbital and zolpidem.

and/or methamphetamine', 'clonazepam' and 'benzodiazepines and similar substances' than the effects estimated in the model in table 4 , under the assumption of additive effects.

\section{DISCUSSION}

The association between the use of alcohol, illicit drugs and medicinal drugs and being investigated for alcohol or drug impairment due to involvement in a road traffic crash was studied using a case-control approach. The substance that produced the highest OR adjusted for gender and age was alcohol (with or without combinations with drugs) $(\mathrm{OR}=976.8)$.

High-risk estimates for both non-fatal and fatal traffic crashes for any use of alcohol with blood alcohol concentrations above the legal limit (blood alcohol concentration (BAC) level of $0.02 \mathrm{~g} / \mathrm{dL}$ ) have also been found in previous studies. ${ }^{12-14}$

The estimation of association between two common drug combinations (amphetamine and/or methamphetamine+THC, amphetamine and/or methamphetamine+benzodiazepines and similar substances), and traffic crash involvement revealed no additive effect of combinations to the ORs. The ORs of both drug interactions approximated the highest of the ORs for the individual substances of the interactions. A third type of combination, clonazepam+benzodiazepines and similar substances, also revealed no additive effect, but for this combination, the OR of the interaction lays in between the individual ORs of clonazepam and the group of benzodiazepines and similar substances.
These results deviate from results of previous casecontrol studies of similar kind that have demonstrated higher risk estimates of traffic crash using combinations of drugs than for use of single drugs. ${ }^{73-16}$ This might be due to the fact that the OR estimation of drug combinations was performed in a different manner in the present study. The OR estimation of combinations of drugs/groups of drugs have been calculated in a logistic regression model together with the calculation of OR estimates of individual substances. The benefit of using this approach is that all substances are added in one model. Thus, the interaction effects for different drugs can only be estimated in a multivariate logistic regression model, rather than in separate marginal models for different drugs. Furthermore, the analysis suggests that ignoring possible interactions may lead to an underestimation of the drug's effects.

In the present study, the prevalence of alcohol among the cases was particularly high $(67 \% \geq 0.02 \mathrm{~g} /$ $\mathrm{dL})$. Previous Norwegian case-control studies that included injured drivers admitted to hospital, ${ }^{12}$ fatally injured drivers ${ }^{13}$ and drivers arrested on suspicion of drugged driving $^{7}$ as case groups found a prevalence of alcohol above $0.02 \mathrm{~g} / \mathrm{dL}$ in $11.5 \%, 25.6 \%$ and $36.2 \%$ of the cases, respectively. All of the studies used random drivers in normal traffic from a Norwegian roadside survey conducted in 2008-2009 as control group ${ }^{17}$ (only differing in numbers depending on the inclusion criteria for the control group of the respective studies). The prevalence of alcohol among the controls in the present study was the same as what was found in the roadside survey from 2008 to 2009 (0.2\%). Considering 
the prevalence of medicinal and illegal drugs among the cases in the present study compared with the study with fatally injured drivers as cases, the differences were minor. Among the cases of the present study, medicinal drugs were found in $18.0 \%$ of the samples and illegal drugs in $15.2 \%$. Among the fatally injured drivers, medicinal drugs were found in $14.8 \%$ of the samples and illegal drugs in $12.8 \% .^{13}$

\section{Limitations}

In this study, we compared concentrations of alcohol and drugs in blood samples from cases and samples of oral fluid from controls. Research has demonstrated that the concentration of most drugs in oral fluid do not reflect very well the corresponding concentration in blood. This is due to several factors such as protein binding of drugs in plasma and $\mathrm{pH}$ of the matrices. However, if equivalent cut-off thresholds are used for oral fluid and blood, the prevalence of positive drug findings in both matrices are comparable. ${ }^{18} 19$ The number of drivers arrested on suspicion of DUI who were tested for alcohol and drugs were low $(n=50)$ in the same period of time as the random drivers were recruited to the roadside survey (September 2014October 2015). Because of this, we chose to include cases from a longer period of time than for the controls to gain more statistical power. This may have increased the likelihood of selection bias by reducing the representativeness of the control group. Fatally injured drivers were also considered as cases for this study, but due to few traffic crashes with fatalities and lack of data, we could not use those drivers as cases.

The high prevalence of alcohol or other psychoactive substances among the cases in the present study indicates a considerable selection bias, as the majority (likely at least $60 \%$ ) of crash-involved drivers was not investigated for alcohol or drug impairment. The case group was chosen because of the detailed blood sample analysis, making it possible to investigate some combinations of psychoactive substances mulitivariately. If including all crash-involved drivers, the estimated ORs would have been very much lower than those presented in this article.

No alcohol positive drivers in the control group had used other substances. Thus OR estimates for crash when driving under the influence of alcohol in combination with other substances could not be made. The cocaine metabolite benzoylecgonine was not analysed in blood samples from cases, only in oral fluid samples from controls. The OR based on detection of cocaine or benzoylecgonine are therefore underestimated.

It is necessary to consider that the results of the model shown in table 5 contain low numbers of observations and consequentially high uncertainty reflected in the wide confidence intervals. Thus, more research studies with greater statistical power are needed to confirm these findings. The statistical methodology presented in this study should be allied in future studies, because combinations of psychoactive substances are prevalent among crash-involved drivers.

Contributors REGJ participated in data collection, performed statistical analysis and drafted the manuscript. HG and STB are responsible for the conceptual development of the research and contributed in the interpretation of statistical analysis and drafting of the manuscript. GR provided substantial supervision and interpretation of the statistical analysis. All authors have critically revised the manuscript and approved the final version.

Funding The roadside survey was funded by the Ministry of Health and Care Services.

Competing interests None declared.

Patient consent Not required.

Ethics approval Handling anonymous data on arrested drivers did not require approval from the Norwegian Higher Prosecuting Authority (legal owner) and did not fall under the scope of the Act on Medical and Health Research; hence, no approval from the Regional Committees for Medical and Health Research Ethics in Norway was required. The roadside survey was approved by the Regional Committees for Medical and Health Research Ethics in Norway (reference no.: 2014/437/REK sør-øst A).

Provenance and peer review Not commissioned; externally peer reviewed.

Data sharing statement № additional data are available.

Open access This is an open access article distributed in accordance with the Creative Commons Attribution Non Commercial (CC BY-NC 4.0) license, which permits others to distribute, remix, adapt, build upon this work non-commercially, and license their derivative works on different terms, provided the original work is properly cited, appropriate credit is given, any changes made indicated, and the use is non-commercial. See: http://creativecommons.org/licenses/by-nc/4.0/.

\section{REFERENCES}

1. Adminaite D, Jost $\mathrm{G}$, Stipdonk $\mathrm{H}$, et al. Ranking EU progress on road safety - 11th road safety performance index report [Internet]. Brussels: European Transport Safety Council, 2017. http://etsc.eu/ 11th-annual-road-safety-performance-index-pin-report-2. (accessed 20 Jul 2017).

2. European Commission. Statistics - accidents data [Internet]. https://ec.europa.eu/transport/road_safety/specialist/statistics_en (accessed 21 Jul 2017).

3. Verstraete A, Legrand SA. Drug use, impaired driving and traffic accidents [Internet]. Lisbon European Monitoring Center for Drugs and Drug Addiction, 2014. http://www.emcdda.europa.eu/ publications/insights/2014/drugs-and-driving. (accessed 21 Jul 2017).

4. Bakke HK, Hansen IS, Bendixen AB, et al. Fatal injury as a function of rurality-a tale of two Norwegian counties. Scand J Trauma Resusc Emerg Med 2013;21:14.

5. Zwerling C, Peek-Asa C, Whitten PS, et al. Fatal motor vehicle crashes in rural and urban areas: decomposing rates into contributing factors. Inj Prev 2005;11:24-8.

6. Jamt REG, Gjerde H, Normann PT, et al. Roadside survey on alcohol and drug use among drivers in the Arctic county of Finnmark (Norway). Traffic Inj Prev 2017;18:681-7.

7. Bogstrand ST, Gjerde H. Which drugs are associated with highest risk for being arrested for driving under the influence? A case-control study. Forensic Sci Int 2014;240:21-8.

8. Kristoffersen L, Smith-Kielland A. An automated alcohol dehydrogenase method for ethanol quantification in urine and whole blood. J Anal Toxicol 2005;29:387-9.

9. Kristoffersen L, Stormyhr LE, Smith-Kielland A. Headspace gas chromatographic determination of ethanol: the use of factorial design to study effects of blood storage and headspace conditions on ethanol stability and acetaldehyde formation in whole blood and plasma. Forensic Sci Int 2006;161:151-7.

10. Vindenes V, Jordbru D, Knapskog AB, et al. Impairment based legislative limits for driving under the influence of non-alcohol drugs in Norway. Forensic Sci Int 2012;219(1-3):1-11.

11. Verstraete A, Knoche A, Jantos R, et al. Per Se Limits - Methods of Defining Cut-Off Values for Zero Tolerance Ghent University [Internet]. Ghent: DRUID (Driving under the Influence of Drugs, Alcohol and Medicines), 2011. http://hdl.handle.net/1854/LU-1988464. (accessed 12 Jul 2017). 
12. Bogstrand ST, Gjerde H, Normann PT, et al. Alcohol, psychoactive substances and non-fatal road traffic accidents-a case-control study. BMC Public Health 2012;12:734.

13. Gjerde H, Christophersen AS, Normann PT, et al. Associations between substance use among car and van drivers in Norway and fatal injury in road traffic accidents: A case-control study. Transp Res Part F Traffic Psychol Behav 2013;17:134-44.

14. Gjerde H, Normann PT, Christophersen AS, et al. Alcohol, psychoactive drugs and fatal road traffic accidents in Norway: a case-control study. Accid Anal Prev 2011;43:1197-203.

15. Kuypers KP, Legrand SA, Ramaekers JG, et al. A case-control study estimating accident risk for alcohol, medicines and illegal drugs. PLoS One 2012;7:e43496.
16. Bernhoft IM, Hels T, Lyckegaard A, et al. Prevalence and risk of injury in europe by driving with alcohol, illicit drugs and medicines. Procedia Soc Behav Sci 2012;48:2907-16.

17. Gjerde H, Christophersen AS, Normann PT, et al. Norwegian roadside survey of alcohol and drug use by drivers (2008-2009). Traffic Inj Prev 2013;14:443-52.

18. Langel K, Gjerde H, Favretto D, et al. Comparison of drug concentrations between whole blood and oral fluid. Drug Test Anal 2014;6:461-71.

19. Gjerde H, Verstraete AG. Estimating equivalent cutoff thresholds for drugs in blood and oral fluid using prevalence regression: a study of tetrahydrocannabinol and amphetamine. Forensic Sci Int 2011;212(1-3):e26-e30. 